\title{
TECNOLOGIAS EDUCACIONAIS NA EDUCAÇÃO DE JOVENS E ADULTOS EM ESCOLAS NA AMAZÔNIA: POTENCIALIZANDO AS PRÁTICAS DOCENTES
}

\author{
EDUCATIONAL TECHNOLOGY \\ FOR YOUTH AND ADULT \\ EDUCATION IN SCHOOLS OF \\ AMAZONIA: POTENTIATING \\ TEACHERS' PRACTICES
}

PA - BRASIL

Ivanildo do Socorro Mendes Gomes* Maria Sueli Corrêa dos Prazeres**

O educador aprende quando se sente "tocado", quando encontra espaço para que sua experiência se converta em fonte de saber. (HERNANDES E SANCHO, 2006).

\section{RESUMO}

O relato de experiência sobre formação de professores para o uso de tecnologias educacionais na Educação de Jovens e Adultos foi desenvolvido no âmbito do projeto de extensão intitulado "Tecnologias em escolas do campo: instrumentalização de professores de escolas ribeirinhas de Cametá para uso de tecnologias educacionais", vinculado ao Programa de Apoio a Projetos de Intervenção Metodológica (PAPIM), vinculado a Pró-Reitoria de Extensão da Universidade Federal do Pará. A Oficina com os professores que atuam na Educação de Jovens e Adultos - EJA, 4a Etapa, da Escola Municipalizada de Ensino Fundamental Izabel Fernandes dos Santos buscou refletir sobre suas práticas, na tentativa de redimensioná-las através do uso pedagógico das tecnologias educacionais. A atividade possibilitou verificar que o uso das tecnologias como recurso didático apresenta possibilidade de transformar as práticas pedagógicas dos professores, porém, ainda faltam estruturas nas escolas e formação para que os docentes as utilizem de forma criativa em suas aulas.

Palavras-chave: Formação de professor; tecnologias educacionais; educação de jovens e adultos.

\section{ABSTRACT}

The experience report about educational technologies for youth and adult education in teacher education derives from the outreach project "Technology in schools: an instrument for teachers of schools located near the riverside of Cametá" which is linked to the assistance program for methodological intervention - PAPIM (Brazilian abbreviation), supported by the Office of Outreach Affairs of Federal University of Pará (UFPA). The workshop was carried out at the elementary school Izabel Fernandes dos Santos for the teachers responsible for youth and adult education - EJA (Brazilian abbreviation). It sought to reflect

* Professor da Universidade Federal do Pará (UFPA), PA - Brasil. E-mail: igomes@ufpa.br

** Professora da Universidade Federal do Pará (UFPA), PA - Brasil. E-mail: suelicorrea@ufpa.br 
on their practices in order to add a new dimension to it through the pedagogical use of educational technologies. It demonstrated that the use of technologies, as teaching resource, may change teachers' pedagogical practices. However, there is still no infrastructure and specific training in schools to include it in teachers' practice.

Keywords: teacher education; educational technologies; youth and adult education.

\section{Introdução}

Este artigo descreve e analisa o desenvolvimento das oficinas teórico-práticas de "Tecnologias Educacionais" desenvolvidas no contexto do projeto de extensão sobre formação docente para o uso de tecnologias em escolas ribeirinhas, na Vila de Porto Grande no Estado do Pará. Ressalta-se que o tema não é novo, mas bastante atual na área da educação, visto que os professores convivem com o desafio de ressignificar o uso pedagógico das tecnologias nos espaços escolares e de potencializar seu trabalho docente, principalmente as suas metodologias de ensino, com o uso das novas tecnologias.

Como ressalta a epígrafe, este trabalho buscou, entre outros objetivos, "tocar" os professores para que reflitam sobre sua prática, na tentativa de redimensioná-la através do uso pedagógico das tecnologias educacionais. A Oficina priorizou a formação pedagógica dos professores que atuam na Educação de Jovens e Adultos - EJA, 4a Etapa, da Escola Municipalizada de Ensino Fundamental Izabel Fernandes dos Santos/PA.

No desenvolvimento da oficina, foram utilizadas as seguintes estratégias: uso de slides para discutir os diferentes contextos históricos e as diferentes concepçóes e configuraçóes da oferta da EJA no Brasil, assim como as principais problemáticas políticas, econômicas e pedagógicas que marcaram $\mathrm{o}$ atendimento educacional da populaçáo jovem e adulta; coleta de dados junto aos professores sobre o uso de tecnologias nas práticas pedagógicas desenvolvidas por eles na EJA; discussóes acerca do uso das tecnologias educacionais existentes na escola, no ensino de alunos jovens e adultos; atividades práticas de elaboração de slides e links na ferramenta PowerPoint.

\section{Vila Porto Grande como lócus da açáo formativa}

A Vila de Porto Grande está localizada no município de Cametá, Pará, às margens do Rio Ajará, afluente do rio Guajará, que por sua vez desagua no Rio Tocantins, em plena Amazônia. Assim, pode-se considerá-la como uma vila ribeirinha. Ela nasceu do movimento de pessoas que chegavam dos centros (colônias) no local (porto), com carregamentos de produtos resultantes do extrativismo (frutas, madeiras, flor-do-campo etc.) e da agricultura. Esta última com maior destaque, devido ao fato de a localidade centrar sua produção principalmente na farinha de mandioca, bastante conhecida pelos moradores das regióes das ilhas por sua qualidade, como também de outras vilas no município de Cametá, e, ainda, de comerciantes de outros municípios. O grande movimento no porto da localidade, principalmente de comerciantes, deu origem ao nome da referida Vila.

A Vila de Porto Grande tem tido um crescimento populacional acentuado nos últimos anos, podendo ser apontados alguns fatores, como: a busca de trabalho por moradores das ilhas próximas que, nos anos de 1980, viram no trabalho com o cultivo de pimenta do reino (plantio, manutenção e colheita) uma forma de melhorar suas vidas, pois era uma atividade que envolvia toda a família, inclusive crianças; há décadas a educação na vila se fortaleceu, com construção de escolas, com a criação em 1986 das séries finais do Ensino Fundamental ( $5^{\mathrm{a}}$ a $8^{\mathrm{a}}$ séries $)$ e mais atualmente com o funcionamento do Ensino Médio, 
através do Sistema Modular de Ensino, o que possibilitou que os jovens permanecessem em Porto Grande e outras famílias mudassem para lá em busca de melhor formação escolar para seus filhos.

Todavia, mesmo sendo uma vila que apresenta uma nucleaçáo populacional com características urbanas, pela sua situação geográfica, ela se encontra afastada da cidade de Cametá/PA, na zona rural. Diante dessa realidade, afirma-se que, no município de Cametá, as Vilas são um meio termo entre o campo e a cidade. Observa-se, nas últimas décadas, a consolidação de uma discussão teórico-prática sobre a Educação do Campo, reafirmando as intencionalidades da luta dos povos que vivem e trabalham no campo por uma educação que dialogue com seus interesses, saberes, experiências de vida, valores culturais e suas especificidades sociais e culturais.

É uma produção teórica sobre educação que nasce e se volta para a realidade da população que se situa fora dos espaços urbanos. No interior dessa teorização, a educação urbana é utilizada como o outro lado da educaçáo que se quer para o campo. Ao se afirmar e reafirmar a educaçáo do e no campo (CALDART, 2002), quer se defender uma concepçáo de educação que considere a identidade dos sujeitos que residem no campo, contrapondo-se à educação ofertada pelo Estado, que desconsidera as especificidades da população do campo. Uma expressão bastante usada pelos defensores da educaçáo do campo para caracterizar a educação que se tem é "educação urbanocêntrica" (HAGE, 2010).

A inquietação é que, no meio dessa discussão, ou melhor, da produção epistemológica, os espaços em que há uma concentração populacional que tem ligação direta com o campo, ou seja, as Vilas, são esquecidas. As Vilas são espaços que se situam entre o campo e a cidade, pois apresentam uma população reduzida em relação à da cidade (não é cidade), mas ao mesmo tempo apresenta uma urbanização e, além disso, a grande maioria tem ligaçáo com o trabalho do campo, mas reside nesses espaços urbanizados.

Tornou-se comum falar dos povos das águas e das florestas, do povo ribeirinho, dos quilombolas, dos assentados etc., mas não se faz referência à população das Vilas. Esse tipo de organizaçáo populacional é muito comum no Município de Cametá/PA, o qual possui cerca de sete Vilas. Esses espaços têm avançado nas últimas décadas na ampliação da oferta de vagas em toda a educação básica (Educação Infantil, Ensino Fundamental e Ensino Médio) e suas modalidades (principalmente na Educação de Jovens e Adultos). Essa ampliação tem, inclusive, produzido uma demanda cada vez maior de candidatos ao Ensino Superior.

\section{A Educaçáo de Jovens e Adultos como foco da açáo formativa}

A Educação de Jovens e Adultos (EJA) tem sua história muito mais tensa do que a história da educaçáo básica, haja vista que as duas se cruzaram e cruzam interesses menos consensuais do que na educação da infância e da adolescência, sobretudo quando os jovens e adultos são trabalhadores, pobres, negros, subempregados, oprimidos, excluídos (ARROYO, 2006). Na Amazônia Tocantina, mais especificamente em Porto Grande, são agricultores de subsistência e filhos de pescadores. 
Neste sentido, foi fundamental para os professores envolvidos com a oficina tratar primeiramente da EJA no que diz respeito à sua história, marcada por diferentes contextos econômicos, políticos e culturais. Essa história começa no Brasil colonial, com uma educação marcadamente catequética (para os indígenas) ou "primeiras letras" (para os colonos). Passa por remodelaçôes nos anos de 1930, com as açóes dos "pioneiros da educaçáo", no sentido de implantar uma nova tendência educacional no Brasil - o escolanovismo - que sofre duras críticas de Paulo Freire, com a nova visão de educação de adultos que levasse, através da dialogicidade, à conscientização e à libertação (tendência libertadora).

Todavia, Freire é exilado pelo golpe militar de 1964, e no lugar dos seus "Círculos de Cultura” é colocado o Movimento Brasileiro de Alfabetização (MOBRAL), organização pedagógica, curricular e politicamente atrelada aos ideais militaristas, que, além de visar manter a sociedade ordeira ao regime, também foi um meio de criar um elevado número de eleitores utilizados como "voto de cabresto", já que analfabeto não podia votar.

Surge ainda no regime militar o Ensino Supletivo que, de acordo com o Parecer 699/72, tem como principais características':

a) quanto ao caráter de suplência dos cursos, eles deveriam ser organizados de três maneiras: sistemática, cuja execução e controle dos estudos se desenvolvem numa relação direta entre professor e aluno; assistemática, quando os estudos se realizavam de forma livre, sem contado imediato entre "transmissor" e "receptor", a exemplo do que ocorre nos programas de TV, rádio e correspondência; e pela combinação de ambas, havendo uma alternância de uma parte assistida (TV, rádio) e outra sistematizada em pequenos estágios diretos; b) no tocante à duração dos cursos, a suplência ficou livre da previsão do mínimo de horas de estudo por seus planos não estarem sujeitos à aprovação, embora houvesse uma cobrança quanto ao planejamento dos cursos; C) em relação ao currículo, tanto os cursos quanto os exames supletivos, quando objetivassem a conclusão de grau com direito a prosseguimento dos estudos, deveriam observar o núcleo comum fixado para o ensino regular; D) no que se refere a avaliação dos resultados, visaria captar e avaliar os conhecimentos e experiências do candidato no momento em que ele se encontrava que, independente do processo, seria o aspecto que mais caracterizaria a concepção de Ensino Supletivo; e) quanto à metodologia, o ensino supletivo deveria ser realizado através da ampla utilização da tecnologia e dos meios de comunicação de massa (utilização de rádio, televisão, correspondência e outros), visando atingir o maior número possível de alunos, o que exigia "preparo adequado" dos professores envolvidos; f) em relação aos professores, o ensino supletivo exigiria um preparo mais amplo e profundo que considerasse o tipo de escola, de aluno, de metodologia a empregar, as peculiaridades locais e as modalidades de atendimento. (BRASIL, 1972).

A Educação de Jovens e Adultos ofertada pela EMEF Izabel Fernandes dos Santos apresenta as características do Ensino Supletivo, o que mostra que a mudança de denominaçáo dessa modalidade de ensino náo se traduziu, como muitos esperavam, em mudanças na concepção de educação, na sua organização curricular, nas estratégias pedagógicas de ensino, na avaliação da aprendizagem e na utilizaçáo dos recursos didáticos diversificados para promover a aprendizagem.

1 Neste texto são elencadas as características mais importantes para esse trabalho.

TECNOLOGIAS EDUCACIONAIS NA EDUCAÇÃO DE JOVENS E ADULTOS EM ESCOLAS NA AMAZÔNIA: POTENCIALIZANDO AS PRÁTICAS DOCENTES 
Na EJA como Suplência observam-se dois grandes objetivos: primeiro, o de se tornar uma estratégia para diminuir o alto índice de pessoas jovens e adultas não alfabetizadas ou analfabetas funcionais, e, para isso, "valia tudo", o que acabou por manter um caráter compensatório e assistencialista do atendimento; segundo, de qualificar ampla massa de máo de obra para as indústrias, por isso o caráter técnico do ensino e, em se tratando do ensino a distância, se pretendia a elevação da escolaridade por vários mecanismos, visto que ela passou a significar maiores chances de emprego e melhor salário, dentro de um contexto de "ordem e progresso".

Considerando que a formação para a cidadania, que é linguagem corrente em todas as esferas sociais (inclusive nas propostas neoliberais), perpassa pela visão do homem e mulher como um todo, náo se pode pautar a educaçáo de jovens e adultos em um currículo que considere esta como um conjunto de açóes compensatórias. Historicamente, essa modalidade esteve sempre relegada a uma posição secundária (ou pior que isso), no quadro mais geral das políticas educacionais no Brasil e, quando ela toma um novo impulso, na década de 90 do século passado, aparece como "destinada a oferecer uma segunda oportunidade de escolarização àqueles que não puderam frequentar a escola na idade apropriada" (BRASIL, 2001, p. 9), ou seja, a característica compensatória aparece presente tanto nas bases legais quanto na proposta curricular, uma vez que, nas atuais formulaçôes curriculares para a educação de jovens e adultos, seus elaboradores tem insistido no discurso que foi consolidado pela Lei 5692/71, em seu Cap. IV, art. 24, que diz: a) suprir a escolarização regular para os adolescentes e adultos que náo a tenham seguido ou concluído na idade própria; b) proporcionar, mediante repetida volta à escola, estudos de aperfeiçoamento ou atualização para os que tenham seguido o ensino regular no todo ou em parte.

Apesar de muitas mudanças no campo teórico e metodológico, advindas com a reformulação da concepção de EJA, essa área apresenta práticas ainda carentes de melhorias significativas em todo o país, visto que os Cursos e Exames Supletivos ainda continuam sendo as principais formas de atendimento da EJA sem mesmo perder seu caráter de suplência, de certificação em massa e de assistencialismo.

\section{As tecnologias educacionais na Educaçáo de Jovens e Adultos}

Diante dessa realidade histórica, verificamos que temos ainda hoje, na maioria das escolas brasileiras - e a Izabel Fernandes dos Santos é uma delas - a herança de uma educação com forte viés militarista, baseada na suplência. Pouco ou nada se modificou quando se trata de Ensino Supletivo, o que leva a afirmar a preocupação em olhar para essa modalidade de ensino no sentido de ressignificá-la na sua multidimensionalidade.

A Escola Municipal de Ensino Fundamental Izabel Fernandes dos Santos é uma instituição pública, localizada na vila de Porto Grande, no município de Cametá/PA, pertencente à regiáo Nordeste do Estado do Pará. Esta escola atende uma clientela de aproximadamente 600 alunos, distribuídos entre o 30 ao 9o ano do Ensino Fundamental. Devido à grande demanda de crianças, jovens e adultos por estudo, as turmas são atendidas em quatro períodos: manhă, intermediário, tarde e noite. À noite, atende a Educação de Jovens e Adultos (EJA) e o Sistema de Organização Modular de Ensino (SOME). 
Quanto aos profissionais que atuam na instituiçáo, são 32 professores, 1 coordenador, 1 diretor, 3 merendeiras, 2 zeladoras, 4 agentes de apoio e segurança. A escola possui uma sala com alguns computadores, no entanto, as máquinas não funcionam devido à falta de manutenção, o que inviabiliza seu uso pelos profissionais que atuam na instituição, assim como pelos alunos. Também existe uma minibiblioteca, que contém livros didáticos e paradidáticos, mas carece de livros técnicos na área da educaçáo para uso dos profissionais, principalmente dos professores, em seu processo de formação em serviço, no sentido da realização de reflexóes fundamentadas sobre suas açôes formativas.

Existe na instituição existe caixa amplificada, micro system, aparelho de DVD, aparelho de TV, entre outros, mas, segundo os professores, não são utilizados nas aulas com a EJA, por se priorizarem os livros didáticos e o quadro. A escola não possui data show, não obstante se tratar de um equipamento muito versátil para o trabalho com slides, filmes, documentários, músicas nas instituições de ensino.

Desta forma, as atividades voltadas para a instrumentalização e potencializaçáo do uso de antigas e novas tecnologias para ensinar jovens e adultos é uma ação fundamental para os professores da EJA da EMEF Izabel Fernandes dos Santos. Essa assertiva revelou-se verdadeira a partir dos relatos dos docentes, que apontaram a limitaçáo no uso de recursos tecnológicos utilizados em práticas pedagógicas quando revelaram a quase exclusividade do uso do quadro-negro, do giz e do livro didático, mesmo que a observaçáo na escola, por parte desta pesquisa, tenha confirmado a existência de outras tecnologias como computadores, aparelho de DVD, televisão, aparelho de som e caixa amplificada.

Nesse sentido, buscou-se enfatizar a potencialidade que as tecnologias educacionais podem acrescentar para as atividades dos professores da EMEF Izabel Fernandes dos Santos, principalmente em se tratando da EJA, que, segundo os relatos dos professores, é marcada por alto índice de desistência de alunos e por atitudes de alguns alunos mais jovens, que não atendem as regras comportamentais da escola (como entrar bêbado na sala de aula), o que prejudica o andamento das aulas.

A questáo principal para essa oficina procurou saber até que ponto o uso de tecnologias educacionais pelos professores da EJA pode tornar suas aulas mais atraentes para os alunos? As discussóes e atividades desenvolvidas partiram do que os professores tinham ao seu alcance, no que se refere às tecnologias educacionais.

O uso de filmes, acompanhados de um roteiro, pode atrair a atenção dos educandos e, com isso, o nível de concentração nas atividades, pois as pessoas, principalmente mais jovens, geralmente gostam de desafios. E o desafio está no fato de eles terem oportunidade de interpretaçáo do conteúdo do que veem, ouvem e sentem, e de como isso está, de certa forma, relacionado com o que aprendem (conteúdo científico) e o que vivem (conteúdo experiencial).

Os documentários que analisam a partir de diferentes pontos de vista a sociodiversidade, a biodiversidade, a economia, a música etc., como instrumento para pensar os diferentes fatos históricos, para pensar as realidades culturais, para evidenciar e valorizar as diferentes linguagens, podem trazer novas formas de interpretaçáo e de produção de novos conhecimentos, sempre balizados pelos saberes produzidos fora da escola, ora na vivência local, ora no acesso de informações acessadas por rádio, televisão e internet, por exemplo. 
A tecnologia que foi apontada pelos professores envolvidos na oficina como aliada da educaçáo é o computador, no sentido de que se acredita na sua potencialidade de chamar a atenção dos alunos, principalmente dos mais jovens, que o usam principalmente para jogar. Mas é de fundamental importância que os professores conheçam e se utilizem dessa tecnologia como recurso didático para ensinar.

Identificou-se que, exceto uma professora que nunca tivera até o momento da oficina nenhum contato com o computador (mas que se mostrou totalmente disposta a aprender informática), a maioria dos professores tem conhecimento básico de computação, mas não tem ideias muito claras de como utilizá-la em seu trabalho com os alunos. Neste sentido, buscou-se mostrar a ferramenta PowerPoint como um programa que pode fazer suas apresentaçóes em slides (inclusive com links), passar vídeos, músicas, entre outras possibilidades. Isso pode dinamizar as aulas e torná-las mais interessantes aos alunos.

\section{Aspectos metodológicos do projeto e a realização das oficinas teórico-prática}

Para a realização do curso de formação, houve incialmente uma visita da equipe do projeto às escolas, com a finalidade de apresentar os objetivos do projeto, bem como fazer o convite para a participaçáo dos docentes no curso e distribuição das fichas de inscriçóes.

Com o intuito de identificar quais tecnologias seriam mais significativas para os docentes, foi realizada uma pesquisa de campo com a aplicação de 30 questionários, a fim de identificar quais tecnologias os docentes gostariam de interagir, conhecer e utilizar em suas práticas pedagógicas. O questionário foi elaborado a partir de questôes de múltipla-escolha, com a finalidade de indicar quais tecnologias os docentes tinham disponíveis em seus locais de trabalho, bem como com quais gostaria de interagir.

Os dados coletados fundamentaram a organização das oficinas teórico-prático, no sentido da seleçáo das tecnologias a serem trabalhadas no curso. A partir dos dados coletados, procedeu-se à análise dos mesmos e a sua disponibilização em gráficos, a fim de se visualizarem os resultados. Finalmente, foram realizados estudos e reflexóes acerca dos resultados obtidos com a pesquisa de campo.

As análises dos dados coletados indicaram que o acesso aos recursos tecnológicos nas escolas ribeirinhas da Amazônia ocorre ainda de forma limitada. Um dos aspectos mais importantes apontados pelos docentes refere-se à ausência de uma política de formaçáo de professor que dê conta de qualificá-los para o uso das tecnologias, sendo que, do total de participantes, $95 \%$ apontaram que não haviam recebido, por parte da Secretaria de Educação, nenhuma formação nessa área.

Sobre a questão do acesso e do uso das tecnologias nas práticas pedagógicas, $77,3 \%$ dos docentes indicaram que o pouco acesso deve-se à falta de familiaridade com as tecnologias, em decorrência da ausência de formação; outros 9,1\% afirmaram que não usam por conta do acesso limitado na escola. Um percentual equivalente também de 9,1\% respondeu que acessam com facilidade as tecnologias; contudo, é importante frisar que tais professores residem na sede do município Cametá, onde o acesso é mais facilitado, seja em suas residências ou em lan house. Outros 4,5\% dos professores 
disseram que não acessam, pois apresentam pouco interesse pelo seu uso na sala de aula, mas ainda assim aceitaram participar do curso.

Em relação ao uso das tecnologias como recurso didático, as análises dos dados indicaram que 40,9\% dos docentes afirmaram não utilizar como recurso didático, ou seja, a maioria dos docentes apontou que não se apropria dos recursos presentes nas escolas. Destes, $27,3 \%$ responderam que usam as tecnologias no processo educativo, enquanto que os que usam raramente representam também 27,3\% dos professores e $4,5 \%$ não opinaram. Ao se somarem os dados dos professores que afirmaram não utilizar e os que raramente utilizam, notar-se-á que a grande maioria não utiliza as tecnologias como recurso didático.

Os dados confirmam o que pontua Cysneiros (1999), quando destaca que na Região Norte as ferramentas tecnológicas são usadas como "inovação conservadora”, ou seja, quando os recursos tecnológicos servem tão somente para questóes administrativas e burocráticas. A utilização das tecnologias como parte integrante de metodologias inovadoras, que contribuam com a melhoria da qualidade do ensino, tem sido um grande desafio, tanto para docentes - que, por limitaçóes de infraestrutura, pessoais e institucionais não fazem a adequada utilização nas aulas -, quanto para os alunos, que perdem a oportunidade de acessar e utilizar as ferramentas tecnológicas.

Os resultados da pesquisa apontaram ainda que os professores tinham maior interesse em conhecer e inserir em suas práticas pedagógicas a internet, o datashow e o computador. Assim, essas ferramentas foram exploradas nas oficinas através das diversas atividades que enfocaram como as ferramentas podem ser utilizadas a favor do processo educativo, assim como foram apontadas suas inúmeras limitaçóes. As oficinas serviram para despertar o interesse dos professores para o uso adequado das ferramentas tecnológicas nas escolas.

As oficinas ocorreram nas dependências da Universidade Federal do Pará - Campus Universitário do Tocantins/Cametá e em mais duas escolas ribeirinhas integrantes do projeto, com docentes do ensino fundamental e que atuam com a Educação de Jovens e Adultos. A oficina teórico-prática realizada na universidade foi facilitada pela existência de diversas tecnologias, entre elas a internet, laboratórios, computadores e data show.

Participaram das oficinas, além dos professores das escolas ribeirinhas, 15 acadêmicos do curso de pedagogia, como bolsistas voluntários; duas bolsistas do projeto e quatro professores da Faculdade de Educação da Universidade Federal do Pará. A finalidade em realizar uma das oficinas no espaço da universidade foi de apresentar aos professores das escolas ribeirinhas o aparato tecnológico que a instituiçáo disponibiliza aos docentes para realizarem suas atividades pedagógicas. Dentre os quais, estáo: internet; data show; laboratório de informática; material para vídeo conferência, entre outros. Destacou-se também que diante de todos estes equipamentos disponíveis aos professores, há também desafios em utilizá-los nas práticas educativas.

As oficinas realizadas nas escolas ribeirinhas ocorreram aos finais de semana, a fim de facilitar a participação dos professores e também para não interferirem no calendário letivo das unidades educacionais. Com base no diagnóstico realizado nas escolas, sobre a existência e o uso pelos docentes dos recursos tecnológicos em suas práticas pedagógicas, foram elaborados os aspectos teóricos e práticos das oficinas. Os monitores foram professores coordenadores do projeto, bolsistas e alunos de graduação dos cursos de pedagogia da UFPA - Campus Universitário do Tocantins - Cametá. 
Para instrumentalizar os docentes a interagirem com os recursos tecnológicos, foram realizadas as oficinas teórico-práticas, nas quais foram trabalhados os conceitos de "Tecnologia" e "Tecnologia educacional", sendo apontados os limites e os desafios para a sua utilizaçấo. Assim sendo, as discussôes serviram para desmistificar que as tecnologias não dizem respeito somente ao computador, internet e data show. Referese também a outras ferramentas, tais como livros, revistas, televisão, DVD, jornais e materiais didáticos.

Desta forma, mesmo diante dos desafios estruturais das escolas ou das precárias condições de acesso aos recursos tecnológicos, é possível trabalhar ainda com os alunos levando em conta as que estão disponíveis em suas realidades.

Sob esta perspectiva, as oficinas contribuíram para aprofundar as discussóes e reflexóes acerca do tema das tecnologias educacionais, procurando enfatizar a importância de seu uso didático-pedagógico nas escolas. As dinâmicas nos grupos de trabalhos apontaram quais tecnologias os docentes gostariam de interagir, bem como suas limitações quanto a seus usos. Foram trabalhadas na oficina diversas estratégias quanto ao uso do computador, internet e data show. Com relação às reflexóes, estas proporcionaram aos participantes identificarem a importância do uso das tecnologias no cotidiano, bem como as limitaçóes que os professores encontram para utilizá-las em suas práticas.

Um dos pontos que chamou a atençáo dos professores, no decorrer da oficina, foi a reflexão em relação ao uso de filmes como recurso didático, não somente no sentido de ampliar a compreensão sobre um determinado conteúdo, mas também de proporcionar a reflexáo a respeito da influência das mídias na sociedade e, especificamente, na escola. O debate possibilitou que os professores refletissem sobre sua realidade, assim como os desafios para a utilização das tecnologias em seus espaços de trabalho nas escolas ribeirinhas.

Assim sendo, as oficinas desenvolveram-se no sentido de potencializar a utilização das tecnologias nas práticas docentes e no desafio de ressignificar o uso pedagógico nas escolas. As reflexóes possibilitaram "tocar" os professores para que reflitam sobre as suas práticas, na tentativa de redimensioná-las por meio do uso pedagógico das tecnologias educacionais. As atividades proporcionadas evidenciaram as limitaçóes, no que tange à utilizaçáo dos recursos tecnológicos nas práticas docentes, no momento em que revelaram a quase exclusividade do uso do quadro, do giz e do livro didático.

As reflexóes acerca da importância e do papel que as tecnologias da informação e comunicaçáo representam em nossas vidas possibilitaram concluir que as tecnologias devem ser utilizadas a favor da transformação social, criando, assim, laços de solidariedade e propiciando o trabalho coletivo. Segundo Apple (1995), o debate sobre o papel da tecnologia na sociedade e na escola náo pode ser pensado apenas com enfoque nas questôes técnicas, isto é, sobre o que podemos ou não fazer com a tecnologia. Devese ir além, cabendo analisar suas causas, efeitos e benefícios para a sociedade e escola.

Diante do exposto, a realização de uma das oficinas ocorreu na Escola Municipal de Ensino Fundamental Izabel Fernandes dos Santos situada no município de Cametá no Estado do Pará, especificamente com os docentes que atuavam com o ensino de EJA. 


\section{Consideraçóes finais}

Quando se pensa em tecnologia educacional, temos que levar em conta que não existe uma tradição de uso dos atuais recursos tecnológicos na escola. Os professores de hoje não tiveram mestres que utilizassem computadores e Internet em suas aulas, portanto, náo têm nenhum modelo para imitar. $\mathrm{O}$ uso da tecnologia necessariamente transforma as práticas pedagógicas existentes em uma escola, pois cada professor tem de descobrir como e quando utilizar o recurso. No entanto, vale ressaltar que nenhuma transformação pode ocorrer sem o devido envolvimento do professor (HERNANDEZ; SANCHO, 2006).

Além disso, o uso de tecnologia educacional na Educação de Jovens e Adultos deve estar articulado com outras dimensóes do processo educativo, como a existência na escola de um currículo fortalecido por uma tessitura coletiva, fruto do envolvimento das pessoas que o elaboram não só baseadas na dimensão técnica, mas também nas dimensôes política, cultural e ética.

Quando refletimos sobre nossas práticas pedagógicas, mais especificamente sobre o uso de tecnologias educacionais e suas implicaçóes curriculares e vice-versa, é fundamental que atentemos para os saberes e fazeres que são verbalizados pelo grupo com o qual estamos envolvidos. Ao contar sua história, cada pessoa conta um pouco de sua vida e, assim, faz uma apresentação de sua leitura de mundo. Uma leitura que pode até não "caber" em nossas "matrizes" ou diretrizes curriculares; no entanto, isso não justifica que a deixemos de lado.

Ao contrário, penso que foi esse deixar de lado - tudo aquilo que não "cabe" em nossos conceitos, categorias e definiçóes acadêmicas - um dos fatores que contribuíram, e que ainda contribuem, para termos índices tão vergonhosos de evasão escolar, de repetência e de baixo aproveitamento escolar, como acontece historicamente na EJA (BARCELOS, 2010). Devemos partir da ideia de currículo que vá além de uma visão de mera lista de conteúdos e de temas a serem contemplados, ou seja, o currículo deve ser entendido como criaçáo cotidiana daqueles que fazem as escolas e como prática que envolve todos os saberes e processos interativos do trabalho pedagógico realizado por alunos e professores.

É necessário colocar as tecnologias educacionais a favor de uma educação que desejamos ser emancipadora de sujeitos, em que professores e alunos sejam protagonistas do processo de formaçáo em que todos aprendem. Não é possível formar um sujeito autônomo, seja no aspecto intelectual ou moral, se for conduzido todo tempo sobre o que aprender, como fazer e quando, impossibilitando-o de pensar sobre cada situaçáo, planejar suas próprias açóes, fazer escolhas conscientes, analisar causa e efeito, bem como responsabilizar-se pelas consequências, diante dos resultados obtidos (SCHEIBEL; LEHENBAUER, 2008).

Daí ser importante uma formação docente que seja capaz de ampliar a reflexão para além das questóes técnicas, mas, sobretudo, situar o sujeito como parte de uma totalidade maior, inserido na dinâmica do sistema capitalista. Para tanto, "a formação dos professores deve levar a um manejo crítico e autônomo tanto das informaçōes quanto das tecnologias, duas dimensōes inseparáveis do conhecimento contemporâneo" (SUBTIL, 2013, p. 412). Desta forma, deve ser priorizada a reflexão 
acerca da relação tecnologia-educaçáo, considerando o contexto de sua produçáo e os significados subjacentes à sua materialidade no campo educacional.

Assim sendo, acredita-se que o curso de formação docente contribuiu para que os docentes da EJA pudessem ser qualificados, não somente no uso e apropriaçáo das tecnologias em suas práticas pedagógicas. Mas, acima de tudo, construíssem subsídios para uma reflexão acerca dos limites e possibilidades da apropriação das tecnologias nas escolas ribeirinhas amazônicas.

\section{Referências}

APPLE, Michael W. Trabalho Docente e textos: Economia Política das Relações de classe e de Gênero em Educação. Trad.: Michael W. Apple, Thomaz Tadeu da Silva, Tina Amado, Vera Maria Moreira. São Paulo: Artes Médicas, 1995.

ARROYO, Miguel. A Educação de Jovens e Adultos em tempos de exclusão. In: BRASIL. Construção Coletiva: contribuições à Educação de Jovens e Adultos. Brasília: MEC; UNESCO, 2006. (Coleção Educação para Todos).

BARCELOS, Valdo. Educação de Jovens e Adultos: currículo e práticas pedagógicas. Petrópolis, RJ: Vozes, 2010.

BRASIL. Ministério da Educação. RECOMEÇO: Supletivo de Qualidade. Programas e Ações para a Educação de Jovens e Adultos. Brasília, DF: 2001.

. Parecer n 699/71. Regulamenta o capítulo IV da Lei 5.692/71. 06 de julho de 1972. Constituição Federal de Educação. Rio de Janeiro.

CALDART, Roseli Salete. Por Uma Educação do Campo: traços de uma identidade em construção. In: KOLLING, Edgar Jorge; CERIOLI, Paulo Ricardo; CALDART, Roseli Salete (Orgs.). Educação do Campo: Identidades e Políticas Públicas. Brasília, DF. Articulação Nacional Por Uma Educação do Campo, 2002. (Coleção Por Uma Educação do Campo, nº 04).

CYSNEIROS, Paulo Gileno. Novas tecnologias na sala de aula: melhorias do ensino ou inovação conservadora? Revista Informática educativa, v.12, n.1, p. 11-24, 1999.

HAGE. Salomão Mufarrej. Políticas de Nucleação e Transporte Escolar: construindo indicadores de qualidade da educação básica nas escolas do campo da Amazônia. Relatório final de Pesquisa, Belém, 2010. (Mimeo).

HERNÁNDEZ, Fernando; SANCHO, Juana Maria. A Formação a partir da experiência vivida. Pátio, Porto Alegre, Artmed, n. 40, nov./jan. 2006-07.

SCHEIBEL, Maria Fani; LEHENBAUER, Silvana (Org.) Saberes e Singularidades na Educação de Jovens e Adultos. Porto Alegre: Mediação, 2008. 
SUBTIL, Maria José Dozza. Tecnologia e meio comunicacionais na educação: a necessária reflexão sobre formação e trabalho docente. Revista HISTEDBR On-line, Campinas, SP, n. 52, p. 402-415, set. 2013. Disponível em: <https://www.fe.unicamp.br/revistas/ged/histedbr/ article/view/5589 >. Acesso em: 18 set. 2014. 